\title{
Bariatric surgery, obesity and liver transplantation
}

\author{
Zunirah Ahmed ${ }^{1}$, Muhammad Ali Khan ${ }^{2}$, Luis Miguel Vazquez-Montesino ${ }^{3}$, Aijaz Ahmed ${ }^{3}$ \\ ${ }^{1}$ Houston Methodist, Houston, TX, USA; ${ }^{2}$ Division of Gastroenterology and Hepatology, University of Alabama Birmingham, AL, USA; ${ }^{3}$ Division \\ of Gastroenterology and Hepatology, Stanford University School of Medicine, Stanford, CA, USA \\ Contributions: (I) Conception and design: A Ahmed, Z Ahmed; (II) Administrative support: A Ahmed; (III) Provision of study materials or patients: \\ A Ahmed; (IV) Collection and assembly of data: Z Ahmed, Khan MA; (V) Data analysis and interpretation: Z Ahmed, A Ahmed, LM Vazquez- \\ Montesino; (VI) Manuscript writing: All authors; (VII) Final approval of manuscript: All authors. \\ Correspondence to: Aijaz Ahmed, MD. Division of Gastroenterology and Hepatology, Stanford University School of Medicine, 750 Welch Road, Suite \\ \# 210, Stanford, CA 94304, USA. Email: aijazahmed@stanford.edu.
}

\begin{abstract}
The obesity epidemic has profoundly impacted the epidemiology and trends of liver disease. In the current era, non-alcoholic fatty liver disease (NAFLD) progressing to non-alcoholic steatohepatitis (NASH) has emerged as the second leading indication for liver transplant (LT) and has been associated with the rising rates of hepatocellular carcinoma (HCC) with and without underlying cirrhosis. Obesity has been associated with poor post-transplant outcomes including lower patient and graft survival; higher risk of post-operative metabolic complications; poor wound healing; and higher infection rates. Bariatric surgery is currently the most effective management of morbid obesity and has been offered to patients both in the pre and post LT setting. The techniques attempted in LT recipients most commonly include sleeve gastrectomy (SG), gastric bypass surgery with few cases of gastric banding and biliopancreatic diversion. However, there is lack of evidence-based data on the optimal management for patients with obesity and who are liver transplant candidates and/or recipients. In the following discussion, we present the highlights from a review of the literature.
\end{abstract}

Keywords: Obesity; liver transplantation (LT)

Received: 04 February 2020; Accepted: 06 July 2020; Published: 25 July 2022.

doi: $10.21037 /$ tgh-2020-14

View this article at: http://dx.doi.org/10.21037/tgh-2020-14

\section{Introduction}

Obesity is an escalating health issue with an estimated prevalence in the United States of approximately 39\% (1). It is a growing problem which has impacted patients with end-stage liver disease by affecting multiple metabolic pathways of the liver (2) and being a crucial risk factor for disease progression (3). Non-alcoholic fatty liver disease (NAFLD) is the liver manifestation of obesity with a clinicopathological disease spectrum ranging from isolated hepatic steatosis, to a more aggressive form of fatty liver disease known as non-alcoholic steatohepatitis (NASH) and ultimately cirrhosis (4). Currently, NASH is emerging as an important causative factor for hepatocellular carcinoma (HCC) $(5,6)$. The cumulative annual incidence rate for developing HCC in patients with NASH-related cirrhosis is approximately $0.34-4.26 \%(7)$. It is also the most rapidly growing etiology for acute on chronic liver failure related hospitalizations and is associated with significant cost burden (8). Furthermore, NASH is the most rapidly growing indication for liver transplantation (LT) in the US since it was assigned as a UNOS diagnostic category in 2001 and is on trajectory to become the most common indication for LT over all $(9,10)$.

\section{Impact of obesity on LT}

Obesity plays a vital role in context of LT and effects can be seen in both pre- and post-transplant setting. 


\section{Pre-LT obesity}

Current American and European guidelines consider a pretransplant body mass index (BMI) $\geq 40 \mathrm{~kg} / \mathrm{m}^{2}$ as a relative contraindication for LT based on poor post-transplant outcomes $(11,12)$. Pre-transplant obesity has been found to be an independent risk factor for long-term mortality, graft dysfunction and increased postoperative events in patients undergoing LT $(13,14)$ and data has shown that patients having concomitant obesity and diabetes mellitus (DM) have a nearly doubled total risk of a complication event and at least tripled the risk of an infective, cardiovascular, or respiratory event (14). Concomitant obesity and diabetes is also associated with reduced post-liver transplant survival with greater impact in older patients and those with HCC (15). A single center study in the UK showed that overweight and obese patients have significantly higher morbidity in terms of infective complications after LT and, consequently, longer hospital stay with increased resource utilization (16). In a large single center study of 785 patients listed for orthotopic liver transplant (OLT) a BMI of $>35 \mathrm{~kg} / \mathrm{m}^{2}$ was associated with NASH cirrhosis $(\mathrm{P}<0.0001)$, higher Model for End-stage Liver Disease (MELD) score, and longer wait times for transplant $(\mathrm{P}=0.002)$ (17). This study categorized patients into six groups by pre-transplant BMI, comprising those with BMIs of $<18.0,18.0-24.9$, $25.0-29.9,30.0-35.0,35.1-40.0$ and $>40 \mathrm{~kg} / \mathrm{m}^{2}$ respectively. No differences were found in operative time, intensive care unit or hospital length of stay, or perioperative complications. Graft and patient survival at intervals up to 3 years were similar between groups. However, when compared with non-obese recipients, recipients with a BMI of $>40 \mathrm{~kg} / \mathrm{m}^{2}$ showed significantly reduced 5 -year graft $(49.0 \%$ versus $75.8 \% ; \mathrm{P}<0.02)$ and patient $(51.3 \%$ versus $78.8 \% ; \mathrm{P}<0.01)$ survival (17). Among patients suffering from obesity, those who are at the extremes of BMI have poor post-transplant outcome. An analysis of 73,538 adult liver transplants showed that patients with extreme BMI $(<18.5$ and $\geq 40)$ when compared to the control had significant differences. Underweight patients were more likely to die from hemorrhagic complications $(\mathrm{P}<0.002)$ and cerebrovascular accidents $(\mathrm{P}<0.04)$. The very severely obese patients had a higher number of infectious complications and cancer events $(\mathrm{P}=0.02)$ leading to death (18). Obesity is also associated with increased incidence of recurrence of HCC for patients with HCC undergoing LT (19). Contrary to most data identifying obesity as a risk factor for graft survival, a retrospective study of UNOS database showed that BMI is not a risk factors for poor patient and both liver and kidney graft survival (20). This study analyzed 7,205 simultaneous liver kidney (SLK) transplants. Of these, 1,677 patients were overweight/obese (OW, BMI 30-39) and 183 were morbidly obese (MO, BMI $\geq 40$ ). $29 \%$ of patients had $\mathrm{NASH}$ in the MO group versus $16.4 \%$ and $4.7 \%$ in the OW and normal weight (NW) groups, respectively. The 1-, 3- and 5-year overall patient survival, kidney and liver graft survivals were comparable between the three groups. Multivariate analysis identified diagnosis of hepatitis C, donor age, diabetes mellitus, and delayed kidney transplant function but not BMI as risk factors for poor patient and both liver and kidney graft survival (20). Additionally, a meta-analysis evaluating long-term impact of pre transplant obesity on patient survival in liver transplant recipients showed that BMI does not specifically impact patient survival. However, obese patients have worse survival when analysis was performed in studies whose cohorts of obese and nonobese patients had similar causes of liver disease (21).

\section{Post-LT obesity}

Obesity is common after solid organ transplantation and it has been shown to be a frequent complication after LT $(22,23)$. Studies from diverse geographical regions describe mean weight gain of 2-9 $\mathrm{kg}$ within the first year after transplantation (24-26). Post-operative weight gain is multifactorial and the incidence of obesity has been found to be affected by BMI at transplantation, donor BMI, marital status, occurrence of acute rejection, and prednisone dose (24). Genetic factor such as carriage of the D allele of the ACE gene is also found to be strong, independent risk factor for excess weight gain after LT (27). The potential impact of post-LT weight gain includes increased risk of new onset diabetes mellitus (NODM) $(28,29)$, metabolic syndrome $(30,31)$ and its associated complications, such as cardiovascular disease (CVD) (32), and de novo NASH in the allograft $(33,34)$.

In a UNOS database study NODM was reported in $26.4 \%$ of recipients (median follow-up, 685 days). Independent predictors of NODM development included recipient age $(\geq 50$ vs. $<50$ years, HR $=1.241)$, African American race ( $\mathrm{HR}=1.147)$, body mass index $(\geq 25 v s .<25$, $\mathrm{HR}=1.186)$, hepatitis $\mathrm{C}(\mathrm{HR}=1.155)$, recipient cirrhosis history (HR $=1.107)$, donor age $(\geq 60 v s .<60$ year, HR $=1.152)$, diabetic donor $(\mathrm{HR}=1.151)$, tacrolimus (tacrolimus vs. cyclosporine, $\mathrm{HR}=1.236$ ), and steroid at discharge (HR $=1.594)$. Living donor transplant $(\mathrm{HR}=0.628)$ and induction 
therapy (HR $=0.816$ ) were associated with a decreased risk of NODM (35). Case-control study by Terto et al. illustrated that pre-existing systemic arterial hypertension and immunosuppression (sodium mycophenolate and tacrolimus) increased the risk of new-onset diabetes after transplant (36). NODM results in increased susceptibility to infectious and CV complications, may lead to reduced longterm graft survival, and has a major impact on the quality of life and survival $(37,38)$.

\section{Types of bariatric surgery (BS) in liver transplant}

Currently, BS is the most effective treatment for morbid obesity and is being utilized in liver transplant candidates. A panel of different techniques primarily including sleeve gastrectomy (SG), Roux-en-Y gastric bypass (GB), with few cases of adjustable gastric banding (AGB) and biliopancreatic diversion are being utilized in LT patients to improve outcome and survival.

\section{$S G$}

SG is currently the most popular bariatric procedure providing sustained weight loss with long-term comorbidity remissions. It is emerging as the preferred BS for LT patients. The surgical technique involves permanent removal of most of the body and fundus of the stomach, typically $60 \%$ to $75 \%$ (39-41). It also results in desirable metabolic changes vie neurohormonal pathways. The resection of gastric fundus reduces ghrelin production and decreases hunger (42). and increased levels of peptideYY and GLP-1, induces satiety (43). Data has shown that SG is effective and safe in treating obesity and related comorbidities $(44,45)$. Laproscopic sleeve gastrectomy (LSG) is also associated with promising results in the treatment on NAFLD. A large prospective cohort study of 91 obese patients reported significant improvement at 1-year post LSG regarding steatosis grade, hepatocyte ballooning, lobular inflammation as well as fibrosis stage $(\mathrm{P}<0.001)(46)$. Likewise, in another study of 71 patients by 30 months after LSG, $53.8 \%$ of cases with borderline NASH and $36.8 \%$ of those with probable NASH showed complete resolution, and $44.7 \%$ of patients with NASH showed improvement. Steatosis improved in $74.6 \%$ of patients $(\mathrm{P}<0.001)(47)$. It is a non-malabsorptive restrictive technique with potential benefit for liver transplant patients due to its lack of influence on the absorption of immunosuppressive agents. SG is also a feasible procedure with a relatively short operating time when compared to laparoscopic gastric bypass (LGB) or laparoscopic adjustable gastric banding (LAGB) (48).

\section{Roux-en-Y gastric bypass (RYGB)}

RYGB has traditionally been the gold standard of BS in the United States, however LSG is now emerging as preferred modality. RYGB involves the creation of a small gastric pouch, typically $30 \mathrm{~mL}$ in size, by segmentation of the stomach with staples or division. The proximal jejunum is then divided about $30 \mathrm{~cm}$ below the ligament of Treitz with the proximal end joining the small bowel about $100 \mathrm{~cm}$ below the point of division and the distal end brought up to form a gastroenterostomy (49). In patients with NASH and morbid obesity, RYGB is linked with a long-lasting beneficial impact on hepatic steatohepatitis and hepatocyte death (50). Laparoscopic RYGB is also reported to be safe and feasible after orthotropic LT (51) and is shown to be successfully performed in liver transplant recipients with morbid obesity and potentially lead to weight loss, correction of metabolic abnormalities, and regression of hepatic dysfunction secondary to recurrent steatosis (52). A single institution study of total of 960 LT patients amongst which $11(1.1 \%)$ had prior BS showed that the most common type of BS was RYGB (n=9) with 1 sleeve gastrectomy and 1 jejunoileal bypass. This study revealed that outcomes of LT patients with prior BS are comparable with other transplant recipients with regards to patient and graft survival and post-LT complication rates (53).

\section{Gastric banding and biliopancreatic diversion}

LAGB is also an alternative non malabsorptive procedure which does not modify the digestive tract and has the lowest postoperative complication rate. A single center study demonstrated durable weight loss with $47 \%$ excess weight loss (EWL) maintained to 15 years after LAGB (54). Gastric banding during transplantation has been shown to be associated with considerable weight loss in patient with morbid obesity and end-stage liver disease (ESLD). Newer innovative methods like placement of an intragastric balloon are also shown to be effective for promoting shortterm weight loss and thereby making the patient fit for liver transplant thereby lowering perioperative morbidity and mortality $(55,56)$. Intragastric balloon followed by biliopancreatic diversion for weight loss has also been reported in a liver transplant recipient (57). 
Table 1 Advantages and disadvantages of different types of bariatric surgeries



Table 1 compares the advantages and disadvantages of different types of bariatric surgeries.

\section{Timing of BS}

\section{Pre-LT}

BS in the setting of NAFLD and NASH has shown promising outcomes in improving steatosis, necroinflammatory activity and hepatic fibrosis $(58,59)$. However once patients develop cirrhosis BS can become challenging and have serious complications. These complications can be worse depending on degree of disease driven by factors such as platelet count, international normalized ratio (INR), bilirubin, and Model for End-Stage Liver Disease (MELD) score. A study performed by Mosko et al. showed that patients with cirrhosis had higher mortality rates when undergoing BS when compared with patients without cirrhosis. Furthermore, patients with decompensated cirrhosis had even higher mortality rates $(0.3 \%$ vs. $0.9 \%$ and $16.3 \%$, respectively, $\mathrm{P}=0.0002$ ). In the study, authors also compared mortality rates between number of surgeries per center. Surgeries performed in more experienced centers had lower mortality rates when compared to those in less experienced centers. For these reasons, patients with cirrhosis should undergo surgery on centers which perform many bariatric surgeries per year (60). A systematic review by Jan et al. reported similar findings in obese patients with pre-diagnosed or incidentally detected compensated cirrhosis. Higher than usual risk of complications and mortality where found in patients with cirrhosis with SG and adjustable gastric banding (AGB) being safest bariatric surgical options for appropriately counseled (61).

To date there are small retrospective reviews and case series examining the role of BS in patients with cirrhosis before liver transplant. A case series by Lin et al. involving laparoscopic sleeve gastrectomy (LSG) in 26 patients awaiting solid organ transplantation showed that LSG is technically feasible, well tolerated and improves candidacy for transplantation. In these patients the mean age was 57 years, and 17 (65\%) were women. Six patients had end-stage renal disease, and 20 patients had end-stage liver disease. There were no deaths, and there were 6 postoperative complications including superficial wound infections, staple line leak, postoperative bleed requiring blood transfusion, transient encephalopathy, and temporary renal insufficiency All patients met the institution's body mass index cutoffs for transplantation by 12 months after the procedure and eight patients eventually underwent solid organ transplant. Six received liver transplants, 1 patient received a combined liver and kidney transplant, and 1 received a kidney transplant (62). A case series of 8 patients by García-Sesma et al. examined the role of LSG in patients with compensated cirrhosis without significant portal hypertension and observed favorable results. Patients showed no postoperative morbidity or mortality and mean percentage excess weight loss was $42.9 \%, 62.2 \%$, and $76.3 \%$ at 3, 6, and 12 months respectively. 2 of the patients had undergone successful OLT highlighting sleeve gastrectomy can improve candidacy in morbidly obese patients awaiting transplantation (63).

A cohort study by Sharpton $e t a l$. of morbidly obese LT candidates highlighted the potential role of SG. In total, 32 LT candidates with a median MELD score of 12 underwent SG. All LT candidates had a history of hepatic decompensation, but complications of liver disease were required to be well controlled at the time of SG. Median pre-SG BMI was $45.0 \mathrm{~kg} / \mathrm{m}^{2}$ [interquartile range 
(IQR), $\left.42.1-49.0 \mathrm{~kg} / \mathrm{m}^{2}\right]$. There were no perioperative deaths or liver-related morbidity. One patient experienced major perioperative morbidity secondary to a gastric leak, which was managed nonoperatively. Median weight loss at 6 and 12 months after SG was $22.0 \mathrm{~kg}$ (IQR, 18.9$26.8 \mathrm{~kg}$ ) and $31.0 \mathrm{~kg}$ (IQR, 23.6-50.3 kg), respectively, corresponding to a percentage of excess body weight loss of $33.4 \%$ and $52.4 \%$. Within 6 months after SG, 28 (88\%) candidates were deemed eligible for LT (64). Smaller studies such as Rebibo et al. $(\mathrm{n}=13)$ and Takata et al. $(\mathrm{n}=6)$ demonstrated similar outcomes of sufficient weight loss (\% EWL $33.0 \%$ and $73.4 \%$ ) with complication rates of $7.7 \%$ and $30.0 \%$, respectively $(65,66)$.

A systematic review on BS for patients in the setting of LT by Lazzati et al. revealed some interesting findings. Studies in the English language on adults reporting on BS prior to, during, or after LT were included. Eleven studies with 56 patients were retrieved. Two studies reported on BS before, two during, and seven after LT. Sleeve gastrectomy was the most common procedure, followed by RYGB, biliopancreatic diversion, and gastric banding. The overall mortality rate was nil in the early postoperative period and $5.3 \%$ in the first postoperative year. The reoperation rate was $12.2 \%(67)$.

\section{$S-L T$}

The major advantage of BS during LT includes single intervention and single recovery phase with lesser risk of perioperative complications associated with portal hypertension. Also combined approach helps in avoiding delays to future procedures due to complications such as rejection, infection, renal insufficiency or disease recurrence or other barriers to weight loss surgery such as insurance coverage and patient hesitation to undergo another invasive procedure. Campsen et al. reported the first case of placement of an adjustable gastric band performed at the time of LT in a morbidly obese patient with hypertension, diabetes, sleep apnea, and venous stasis. The patient did well postoperatively and lost approximately $45 \%$ of excess weight by 6 months, with her BMI falling from 42 to 34 . Operative time was extended by only 30 minutes (68).

Combined LT and sleeve gastrectomy is reported to have potential advantages in terms of allograft and patient survival and maintenance of weight loss that will ultimately reduce obese related co-morbidities (69). In a series from the Mayo Clinic published in 2012 (70), a total of 7 patients underwent a liver transplant combined with sleeve gastrectomy. The decision to perform sleeve gastrectomy rather than a gastric bypass was attributable to the absence of malabsorption that accompanies the sleeve gastrectomy and preserved endoscopic access to the biliary tree after the transplant. Concurrent placement of an adjustable gastric band was not performed, owing to its lesser efficacy in comparison with sleeve gastrectomy. There were no mortalities in this series, and allograft function was preserved without incident. The mean BMI was 48 at transplant and 29 postoperatively at the last follow-up. None of the patients had steatosis on follow-up, based on annual protocol ultrasonography. One patient developed a gastric staple-line leak and required multiple operations with early graft dysfunction, but eventually recovered and was able to be discharged home. There was excessive weight loss down to a BMI of 20 in 1 patient, and another required thymoglobulin for rejection, but all were found to have normal allograft function on routine follow-up. All patients received standard posttransplant immunosuppression and experienced no difficulty with tacrolimus dosing (70). In 2018, Mayo Clinic updated their prior experience of patients who underwent S-LT and reported on long-term outcomes for obese patients undergoing LT, including a noninvasive weight loss program and combined LT and SG $(70,71)$. The mean BMI at the time of transplant for the S-LT group was $47 \mathrm{~kg} / \mathrm{m}^{2}$ with a reduction in BMI to $31 \mathrm{~kg} / \mathrm{m}^{2}$ at last followup. Complication rates were unchanged from the prior study (71). At 3 years follow-up, S-LT patients maintained a significantly higher percentage of total body weight loss when compared with obese LT patients who did not undergo the combined procedure (LT 3.9\% $\pm 13.3 \%$ versus S-LT $34.8 \% \pm 17.3 \% ; \mathrm{P}<0.001)$. Patients in the S-LT also had a lower prevalence of hypertension, insulin resistance, and hepatic steatosis, and they required fewer lipid agents at last follow-up (71). There are 2 additional patient series/ reports of low-level evidence of S-LT and SG from Italy and Israel who similarly report robust weight loss and no significant perioperative complications. However, these are limited by short interval follow-up (5 and 13 months) and small sample size with a combined 4 patients between these 2 reports $(69,72)$.

\section{Post-LT}

Like the case series on pre-LT patients, Lin et al. also analyzed the safety and feasibility of BS after LT. Nine morbidly obese patients with prior liver transplants underwent sleeve gastrectomy Sleeve gastrectomy was 
Table 2 Advantages and disadvantages of timing of bariatric surgery in the setting of liver transplantation

\begin{tabular}{lll}
\hline Timings & Advantages & Disadvantages \\
\hline Before LT & $\begin{array}{l}\text { Decreased weight and resolution of comorbidities before LT with } \\
\text { benefits remaining after transplant }\end{array}$ & $\begin{array}{l}\text { Increased cost with } 2 \text { separate hospitalizations, } \\
\text { increased patient discomfort, delay of LT }\end{array}$ \\
During LT & $\begin{array}{l}\text { Minimizes cost and patient discomfort, resolution of obesity- } \\
\text { related comorbidities after LT }\end{array}$ & $\begin{array}{l}\text { Complex procedure } \\
\text { After LT }\end{array}$ \\
$\begin{array}{lll}\text { Decreases obesity-related comorbidities after LT } \\
\end{array}$ & & $\begin{array}{l}\text { Increased risk of wound dehiscence and infection } \\
\text { in the setting of post-LT immunosuppression, } \\
\text { increased adhesions }\end{array}$ \\
\hline
\end{tabular}

LT, liver transplantation.

preferred over gastric banding to avoid foreign body implantation, and over gastric bypass to maintain endoscopic access to the biliary system and reduce surgical complexity. Sleeve gastrectomy was performed laparoscopically in eight patients and as an open procedure in one patient. Excess weight loss averaged $55.5 \%$ at 6 months. In the first 30 days, there were three complications in three patients: mesh dehiscence after a synchronous incisional hernia repair, bile leak from the liver surface requiring laparoscopic drainage, and postoperative dysphagia that required reoperation. Renal function and levels of immunosuppression remained stable. There were no episodes of graft rejection and 3 months liver function tests remained stable (73). Another large case series by Tsamalaidze et al. was a retrospective case control study with 2:1 matching to the general population who underwent LSG (74). The \%EWL was robust but significantly lower in the post-OLT group as compared with the general population $(45.2 \%$ versus $53.7 \% ; \mathrm{P}<0.001)$. There were similar rates of resolution of obesity-associated conditions in each group. Serum levels of immunosuppression before and after LSG in the post-OLT group were also analyzed and found to have no difference (74). Similarly, a retrospective case-control study revealed that LSG after OLT appears to have similar outcomes to LSG in non-OLT patients with no changes in dosage of immunosuppressive medications or any liver complication (74). This reiterates findings in a prospective study of immunosuppression in post-LSG patients, where no difference in pharmacokinetics was also noted (75). LSG has also shown to improve improved steatosis and reduced obesity and obesity-associated comorbidities in obese, posttransplant recipients with recurrent and de novo nonalcoholic steatohepatitis (76). Small case series by Khoraki et al. $(\mathrm{n}=10)$ and Osseis $(\mathrm{n}=6)$ further demonstrated that LSG, in selected patients with severe obesity after solid organ transplantation is associated with significant weight loss, improvement or resolution of obesity-related ailments, and preservation or improvement of graft function $(77,78)$.

Table 2 compares the advantages and disadvantages of timing of BS in the setting of LT.

\section{Liver dysfunction after BS}

There is limited data on deterioration of liver function and liver failure after performing bariatric operations A single center case study analyzing 10 patients who developed liver dysfunction after BS showed that liver dysfunction occurred after a median postoperative time of 15 months. Liver steatosis/fibrosis occurred in 70\%, cirrhosis in 30\% of patients, and led to fatigue (90\%), ascites (70\%), hepatic encephalopathy (30\%), and upper gastrointestinal bleeding (20\%). Elevation of transaminases, impairment of coagulation parameters, thrombocytopenia, and hypoalbuminemia were present in $70,80,70$, and $100 \%$, respectively (79).

A systematic review and meta-analysis of fourteen studies including 36 patients listed for LT after BS reported that liver failure developed at median of 20 months after BS. Four patients $(11.1 \%)$ died while on the waiting list for LT, and 4 more $(12.5 \%)$ died after LT. Twenty-one patients (65.6\%) had their BS procedure reversed (1 patient before, 15 patients during, and 5 patients after LT, respectively). The limitations of this review is small number of studies and that majority of patients had a jejunoileal bypass a technique that has been virtually abandoned for many years and is of no interest in current clinical practice (80).

The current surgical techniques are considered quite safe however a case series by Beer $e t$ al. highlighted major liver function impairment after RYGB and one-anastomosis gastric bypass (OAGB). In total, 7 patients were observed. Deterioration of liver function occurred after RYGB 
$(\mathrm{n}=5)$, OAGB $[\mathrm{n}=1(+1 /$ conversion into OAGB $)]$ and even gastric banding $(\mathrm{n}=1)$ after a median postoperative time of 6 months (range, 2-24 months). Clinical symptoms varied from fatigue $(86 \%)$ to ascites $(57 \%)$, hepatic encephalopathy (29\%), and variceal bleeding (14\%). Elevation of transaminases, impairment of coagulation parameters, thrombocytopenia and hypalbuminemia were present in $57 \%, 86 \%, 71 \%$, and $100 \%$, respectively. Liver cirrhosis was proven by biopsy in 3 out of 7 patients and a $100 \%$ steatosis was present in 1 of the patients. In 5 patients bypass (BP) length reduction or reversal was performed and led to an improvement of symptoms, determinable also by imaging, histology and blood exam. In one patient LT was needed, one patient died in septic shock and decompensated liver disease (81). Malnutrition after malabsorptive bariatric procedures can lead to hepatic failure leading to death $(82,83)$ or requiring OLT as the only therapeutic option (84). Portal vein thrombosis (PVT) is a rare but well recognized complication of BS, particularly SG. The presentation of PVT is heterogenous and in rare cases can cause histologic liver abnormalities, such as nodular regenerative hyperplasia (NRH) requiring OLT as the only therapeutic option (85).

\section{Conclusions}

The role of BS in the liver transplant patients remains an arena to be fully explored. The impact of BS and long-term outcomes are well understood in non-transplant population however less in known about the impact of weight loss procedures for liver transplant patients. Sleeve gastrectomy has shown to be more promising when compare to other procedures in LT patients with regards to long-term weight loss and malabsorption. BS is relatively safe however there is limited data on liver dysfunction after weight loss surgeries. There is need for evidence-based management of hepatic failure post-BS. The optimal timing of BS in setting of LT remains controversial. Large multicenter randomized studies are needed to devise an optimal management plan and strategy for this patient population.

\section{Acknowledgments}

Funding: None.

\section{Footnote}

Provenance and Peer Review: This article was commissioned by the Guest Editors (Sanjaya K. Satapathy, David Bernstein,
Nitzan Roth) for the series "Liver Transplantation in NASH and ALD" published in Translational Gastroenterology and Hepatology. The article has undergone external peer review.

Conflicts of Interest: All authors have completed the ICMJE uniform disclosure form (available at https://tgh. amegroups.com/article/view/10.21037/tgh-2020-14/coif). The series "Liver Transplantation in NASH and ALD" was commissioned by the editorial office without any funding or sponsorship. The authors have no other conflicts of interest to declare.

Ethical statement: The authors are accountable for all aspects of the work in ensuring that questions related to the accuracy or integrity of any part of the work are appropriately investigated and resolved.

Open Access Statement: This is an Open Access article distributed in accordance with the Creative Commons Attribution-NonCommercial-NoDerivs 4.0 International License (CC BY-NC-ND 4.0), which permits the noncommercial replication and distribution of the article with the strict proviso that no changes or edits are made and the original work is properly cited (including links to both the formal publication through the relevant DOI and the license). See: https://creativecommons.org/licenses/by-nc-nd/4.0/.

\section{References}

1. Hales CM, Carroll MD, Fryar CD, et al. Prevalence of Obesity Among Adults and Youth: United States, 20152016. NCHS Data Brief 2017;(288):1-8.

2. Corey KE, Kaplan LM. Obesity and liver disease: the epidemic of the twenty-first century. Clin Liver Dis 2014;18:1-18.

3. Manne V, Saab S. Impact of nutrition and obesity on chronic liver disease. Clin Liver Dis 2014;18:205-18.

4. Farrell GC, Larter CZ. Nonalcoholic fatty liver disease: from steatosis to cirrhosis. Hepatology (Baltimore, $\mathrm{Md}$ ) 2006;43:S99-112.

5. Yu J, Shen J, Sun TT, et al. Obesity, insulin resistance, NASH and hepatocellular carcinoma. Semin Cancer Biol 2013;23:483-91.

6. Charrez B, Qiao L, Hebbard L. Hepatocellular carcinoma and non-alcoholic steatohepatitis: The state of play. World J Gastroenterol 2016;22:2494-502.

7. White DL, Kanwal F, El-Serag HB. Association between nonalcoholic fatty liver disease and risk for hepatocellular 
cancer, based on systematic review. Clin Gastroenterol Hepatol 2012;10:1342-59.e2.

8. Axley $\mathrm{P}$, Ahmed Z, Arora S, et al. NASH Is the Most Rapidly Growing Etiology for Acute-on-Chronic Liver Failure-Related Hospitalization and Disease Burden in the United States: A Population-Based Study. Liver Transpl 2019;25:695-705.

9. Cholankeril G, Wong RJ, Hu M, et al. Liver Transplantation for Nonalcoholic Steatohepatitis in the US: Temporal Trends and Outcomes. Dig Dis Sci 2017;62:2915-22.

10. Wong RJ, Aguilar M, Cheung R, et al. Nonalcoholic steatohepatitis is the second leading etiology of liver disease among adults awaiting liver transplantation in the United States. Gastroenterology 2015;148:547-55.

11. Murray KF, Carithers RL, Jr. AASLD practice guidelines: Evaluation of the patient for liver transplantation. Hepatology (Baltimore, Md) 2005;41:1407-32.

12. EASL Clinical Practice Guidelines: Liver transplantation. Journal of hepatology 2016;64:433-85.

13. Thuluvath PJ, Yoo HY, Thompson RE. A model to predict survival at one month, one year, and five years after liver transplantation based on pretransplant clinical characteristics. Liver Transpl 2003;9:527-32.

14. Dare AJ, Plank LD, Phillips AR, et al. Additive effect of pretransplant obesity, diabetes, and cardiovascular risk factors on outcomes after liver transplantation. Liver Transpl 2014;20:281-90.

15. Adams LA, Arauz O, Angus PW, et al. Additive impact of pre-liver transplant metabolic factors on survival post-liver transplant. J Gastroenterol Hepatol 2016;31:1016-24.

16. Hakeem AR, Cockbain AJ, Raza SS, et al. Increased morbidity in overweight and obese liver transplant recipients: a single-center experience of 1325 patients from the United Kingdom. Liver Transpl 2013;19:551-62.

17. Conzen KD, Vachharajani N, Collins KM, et al. Morbid obesity in liver transplant recipients adversely affects longterm graft and patient survival in a single-institution analysis. HPB (Oxford) 2015;17:251-7.

18. Dick AA, Spitzer AL, Seifert CF, et al. Liver transplantation at the extremes of the body mass index. Liver Transpl 2009;15:968-77.

19. Mathur A, Franco ES, Leone JP, et al. Obesity portends increased morbidity and earlier recurrence following liver transplantation for hepatocellular carcinoma. HPB (Oxford) 2013;15:504-10.

20. Yu JW, Gupta G, Kang L, et al. Obesity does not significantly impact outcomes following simultaneous liver kidney transplantation: review of the UNOS database - a retrospective study. Transpl Int 2019;32:206-17.

21. Saab S, Lalezari D, Pruthi P, et al. The impact of obesity on patient survival in liver transplant recipients: a metaanalysis. Liver Int 2015;35:164-70.

22. Mazuelos F, Abril J, Zaragoza C, et al. Cardiovascular morbidity and obesity in adult liver transplant recipients. Transplant Proc 2003;35:1909-10.

23. Barnard A, Konyn P, Saab S. Medical Management of Metabolic Complications of Liver Transplant Recipients. Gastroenterol Hepatol (N Y) 2016;12:601-8.

24. Everhart JE, Lombardero M, Lake JR, et al. Weight change and obesity after liver transplantation: incidence and risk factors. Liver Transpl Surg 1998;4:285-96.

25. Rezende Anastácio L, Garcia Ferreira L, Costa Liboredo J, et al. Overweight, obesity and weight gain up to three years after liver transplantation. Nutr Hosp 2012;27:1351-6.

26. Richards J, Gunson B, Johnson J, Neuberger J. Weight gain and obesity after liver transplantation. Transpl Int 2005;18:461-6.

27. Toniutto P, Fabris C, Minisini R, et al. Weight gain after liver transplantation and the insertion/deletion polymorphism of the angiotensin-converting enzyme gene. Transplantation 2005;79:1338-43.

28. Hasse JM. Nutritional implications of liver transplantation. Henry Ford Hosp Med J 1990;38:235-40.

29. Levitsky J, Cohen SM. The liver transplant recipient: what you need to know for long-term care. J Fam Pract 2006;55:136-44.

30. Bianchi G, Marchesini G, Marzocchi R, et al. Metabolic syndrome in liver transplantation: relation to etiology and immunosuppression. Liver Transpl 2008;14:1648-54.

31. Lattanzi B, D'Ambrosio D, Tavano D, et al. Weight Gain and De Novo Metabolic Disorders after Liver Transplantation. Nutrients 2019;11:3015.

32. Fussner LA, Heimbach JK, Fan C, et al. Cardiovascular disease after liver transplantation: When, What, and Who Is at Risk. Liver Transpl 2015;21:889-96.

33. Taneja S, Roy A. Nonalcoholic steatohepatitis recurrence after liver transplant. Transl Gastroenterol Hepatol 2020;5:24.

34. Cotter TG, Charlton M. Nonalcoholic Steatohepatitis After Liver Transplantation. Liver Transpl 2020;26:141-59.

35. Kuo HT, Sampaio MS, Ye X, et al. Risk factors for newonset diabetes mellitus in adult liver transplant recipients, an analysis of the Organ Procurement and Transplant Network/United Network for Organ Sharing database. 
Transplantation 2010;89:1134-40.

36. Terto SV, Araujo ST, Negreiros F, et al. Risk Factors Associated With New-Onset Diabetes After Liver Transplant: A Case Control Study. Transplant Proc 2019;51:1956-61.

37. Baid S, Cosimi AB, Farrell ML, et al. Posttransplant diabetes mellitus in liver transplant recipients: risk factors, temporal relationship with hepatitis $\mathrm{C}$ virus allograft hepatitis, and impact on mortality. Transplantation 2001;72:1066-72.

38. Weir MR, Fink JC. Risk for posttransplant Diabetes mellitus with current immunosuppressive medications. Am J Kidney Dis 1999;34:1-13.

39. Vu L, Switzer NJ, De Gara C, et al. Surgical interventions for obesity and metabolic disease. Best Pract Res Clin Endocrinol Metab 2013;27:239-46.

40. Colquitt JL, Picot J, Loveman E, et al. Surgery for obesity. Cochrane Database Syst Rev 2009;(2):CD003641.

41. Butte JM, Devaud N, Jarufe NP, et al. Sleeve gastrectomy as treatment for severe obesity after orthotopic liver transplantation. Obes Surg 2007;17:1517-9.

42. Langer FB, Reza Hoda MA, Bohdjalian A, et al. Sleeve gastrectomy and gastric banding: effects on plasma ghrelin levels. Obes Surg 2005;15:1024-9.

43. McCarty TR, Jirapinyo P, Thompson CC. Effect of Sleeve Gastrectomy on Ghrelin, GLP-1, PYY, and GIP Gut Hormones: A Systematic Review and Meta-analysis. Ann Surg 2020;272:72-80.

44. Li ZJ, Yu JC, Kang WM, et al. Effectiveness of Laparoscopic Sleeve Gastrectomy in Treating Obesity and Its Co-morbidities. Zhongguo Yi Xue Ke Xue Yuan Xue Bao 2018;40:610-6.

45. Salman AA, Sultan AAEA, Abdallah A, et al. Effect of weight loss induced by laparoscopic sleeve gastrectomy on liver histology and serum adipokine levels. J Gastroenterol Hepatol 2020;35:1769-73.

46. Salman MA, Salman AA, Abdelsalam A, et al. Laparoscopic Sleeve Gastrectomy on the Horizon as a Promising Treatment Modality for NAFLD. Obes Surg 2020;30:87-95.

47. Salman MA, Mikhail HMS, Nafea MA, et al. Impact of laparoscopic sleeve gastrectomy on fibrosis stage in patients with child-A NASH-related cirrhosis. Surg Endosc 2021;35:1269-77.

48. Trastulli S, Desiderio J, Guarino S, et al. Laparoscopic sleeve gastrectomy compared with other bariatric surgical procedures: a systematic review of randomized trials. Surg Obes Relat Dis 2013;9:816-29.
49. Pories WJ. Bariatric surgery: risks and rewards. J Clin Endocrinol Metab 2008;93:S89-96.

50. Schneck AS, Anty R, Patouraux S, et al. Roux-En Y Gastric Bypass Results in Long-Term Remission of Hepatocyte Apoptosis and Hepatic Histological Features of Nonalcoholic Steatohepatitis. Front Physiol 2016;7:344.

51. Tichansky DS, Madan AK. Laparoscopic Roux-en-Y gastric bypass is safe and feasible after orthotopic liver transplantation. Obes Surg 2005;15:1481-6.

52. Duchini A, Brunson ME. Roux-en-Y gastric bypass for recurrent nonalcoholic steatohepatitis in liver transplant recipients with morbid obesity. Transplantation 2001;72:156-9.

53. Safwan M, Collins KM, Abouljoud MS, et al. Outcome of liver transplantation in patients with prior bariatric surgery. Liver Transpl 2017;23:1415-21.

54. O'Brien PE, MacDonald L, Anderson M, et al. Long-term outcomes after bariatric surgery: fifteen-year follow-up of adjustable gastric banding and a systematic review of the bariatric surgical literature. Ann Surg 2013;257:87-94.

55. Choudhary NS, Saigal S, Saraf N, et al. Innovative approach using an intragastric balloon for weight loss in a morbidly obese patient undergoing liver transplantation. Liver Transpl 2013;19:235.

56. Choudhary NS, Puri R, Saraf N, et al. Intragastric balloon as a novel modality for weight loss in patients with cirrhosis and morbid obesity awaiting liver transplantation. Indian J Gastroenterol 2016;35:113-6.

57. Gentileschi P, Venza M, Benavoli D, et al. Intragastric balloon followed by biliopancreatic diversion in a liver transplant recipient: a case report. Obes Surg 2009;19:1460-3.

58. Weiner RA. Surgical treatment of non-alcoholic steatohepatitis and non-alcoholic fatty liver disease. Dig Dis 2010;28:274-9.

59. Furuya CK, Jr, de Oliveira CP, de Mello ES, et al. Effects of bariatric surgery on nonalcoholic fatty liver disease: preliminary findings after 2 years. J Gastroenterol Hepatol 2007;22:510-4.

60. Mosko JD, Nguyen GC. Increased perioperative mortality following bariatric surgery among patients with cirrhosis. Clin Gastroenterol Hepatol 2011;9:897-901.

61. Jan A, Narwaria M, Mahawar KK. A Systematic Review of Bariatric Surgery in Patients with Liver Cirrhosis. Obes Surg 2015;25:1518-26.

62. Lin MY, Tavakol MM, Sarin A, et al. Laparoscopic sleeve gastrectomy is safe and efficacious for pretransplant candidates. Surg Obes Relat Dis 2013;9:653-8. 
63. García-Sesma A, Calvo J, Manrique A, et al. Morbidly Obese Patients Awaiting Liver Transplantation-Sleeve Gastrectomy: Safety and Efficacy From a Liver Transplant Unit Experience. Transplant Proc 2019;51:33-7.

64. Sharpton SR, Terrault NA, Posselt AM. Outcomes of Sleeve Gastrectomy in Obese Liver Transplant Candidates. Liver Transpl 2019;25:538-44.

65. Takata MC, Campos GM, Ciovica R, et al. Laparoscopic bariatric surgery improves candidacy in morbidly obese patients awaiting transplantation. Surg Obes Relat Dis 2008;4:159-64; discussion 164-5.

66. Rebibo L, Gerin O, Verhaeghe P, et al. Laparoscopic sleeve gastrectomy in patients with NASH-related cirrhosis: a case-matched study. Surg Obes Relat Dis 2014;10:405-10; quiz 565.

67. Lazzati A, Iannelli A, Schneck AS, et al. Bariatric surgery and liver transplantation: a systematic review a new frontier for bariatric surgery. Obes Surg 2015;25:134-42.

68. Campsen J, Zimmerman M, Shoen J, et al. Adjustable gastric banding in a morbidly obese patient during liver transplantation. Obes Surg 2008;18:1625-7.

69. Tariciotti L, D'Ugo S, Manzia TM, et al. Combined liver transplantation and sleeve gastrectomy for end-stage liver disease in a bariatric patient: First European case-report. Int J Surg case Rep 2016;28:38-41.

70. Heimbach JK, Watt KD, Poterucha JJ, et al. Combined liver transplantation and gastric sleeve resection for patients with medically complicated obesity and end-stage liver disease. Am J Transplant 2013;13:363-8.

71. Zamora-Valdes D, Watt KD, Kellogg TA, et al. Longterm outcomes of patients undergoing simultaneous liver transplantation and sleeve gastrectomy. Hepatology (Baltimore, Md) 2018;68:485-95.

72. Nesher E, Mor E, Shlomai A, et al. Simultaneous Liver Transplantation and Sleeve Gastrectomy: Prohibitive Combination or a Necessity? Obes Surg 2017;27:1387-90.

73. Lin MY, Tavakol MM, Sarin A, et al. Safety and feasibility of sleeve gastrectomy in morbidly obese patients following liver transplantation. Surg Endosc 2013;27:81-5.

doi: $10.21037 /$ tgh-2020-14

Cite this article as: Ahmed Z, Khan MA, VazquezMontesino LM, Ahmed A. Bariatric surgery, obesity and liver transplantation. Transl Gastroenterol Hepatol 2022;7:25.
74. Tsamalaidze L, Stauffer JA, Arasi LC, et al. Laparoscopic Sleeve Gastrectomy for Morbid Obesity in Patients After Orthotopic Liver Transplant: a Matched Case-Control Study. Obes Surg 2018;28:444-50.

75. Hade AM, Shine AM, Kennedy NP, et al. Both undernutrition and obesity increase morbidity following liver transplantation. Ir Med J 2003;96:140-2.

76. Ayloo S, Guss C, Pentakota SR, et al. Minimally Invasive Sleeve Gastrectomy as a Surgical Treatment for Nonalcoholic Fatty Liver Disease in Liver Transplant Recipients. Transplant Proc 2020;52:276-83.

77. Khoraki J, Katz MG, Funk LM, et al. Feasibility and outcomes of laparoscopic sleeve gastrectomy after solid organ transplantation. Surg Obes Relat Dis 2016;12:75-83.

78. Osseis M, Lazzati A, Salloum C, et al. Sleeve Gastrectomy After Liver Transplantation: Feasibility and Outcomes. Obes Surg 2018;28:242-8.

79. Eilenberg M, Langer FB, Beer A, et al. Significant Liver-Related Morbidity After Bariatric Surgery and Its Reversal-a Case Series. Obes Surg 2018;28:812-9.

80. Addeo P, Cesaretti M, Anty R, et al. Liver transplantation for bariatric surgery-related liver failure: a systematic review of a rare condition. Surg Obes Relat Dis 2019;15:1394-401.

81. Eilenberg M, Langer FB, Beer A, et al. Significant Liver-Related Morbidity After Bariatric Surgery and Its Reversal-a Case Series. Obes Surg 2018;28:812-9.

82. Mayo Ossorio MA, Pacheco Garcia JM, Pérez Gomar D, et al. Long-term fulminant hepatic failure in patients undergoing gastric bypass for morbid obesity. Nutr Hosp 2015;32:430-4.

83. Lammers WJ, van Tilburg AJ, Apers JA, et al. Liver failure caused by prolonged state of malnutrition following bariatric surgery. World J Hepatol 2018;10:396-9.

84. Ralki M, Cassiman D, Van Dongen J, et al. Liver failure after long-limb gastric bypass. Clin Res Hepatol Gastroenterol 2017;41:e32-7.

85. Danion J, Genser L, Scatton O. Sleeve Gastrectomy: You Might Lose your Liver! Obes Surg 2019;29:350-2. 